\title{
N-Methylation of BI 187004 by Thiol S-Methyltransferase ${ }^{\S}$
}

\author{
Hlaing H. Maw, Xingzhong Zeng, Scot Campbell, Mitchell E. Taub, and Aaron M. Teitelbaum \\ Drug Metabolism and Pharmacokinetics (H.H.M., M.E.T., A.M.T.), Chemical Development (X.Z.), and Material and Analytical \\ Sciences (S.C.), Boehringer Ingelheim Pharmaceuticals, Inc., Ridgefield, Connecticut
}

Received November 29, 2017; accepted March 5, 2018

\begin{abstract}
BI 187004, an 11ß-hydroxysteroid dehydrogenase 1 inhibitor, was administered once daily for 14 days to eight patients with type 2 diabetes mellitus. $\mathbf{N}$-methylation was identified as a major biotransformation pathway. In four patients treated with BI 187004, the plasma exposure of an $\mathbf{N}$-methylbenzimidazole metabolite [N-methylbenzimidazole regioisomer 1 (M1)] was 7-fold higher than the remaining four patients, indicating a substantial degree of metabolic variation. To identify the methyltransferase enzymes responsible for $\mathbf{N}$-methylation, BI 187004 was incubated with human liver microsomes (HLM), human kidney microsomes (HKM), and their respective cytosolic preparations in the presence and absence of isoformselective chemical inhibitors. Additionally, BI 187004 was incubated with several human recombinant methyltransferases: catechol 0 -methyltransferase (rhCOMT), histamine $\mathbf{N}$-methyltransferase (rhHNMT), nicotinamide $\mathrm{N}$-methyltransferase (rhNNMT), glycine $\mathbf{N}$-methyltransferase
\end{abstract}

(rhGNMT), and thiopurine S-methyltransferase (rhTPMT). M1 was principally observed in HLM and HKM incubations, minimally formed in liver and kidney cytosol, and not formed during incubations with recombinant methyltransferase enzymes. In all microsomal and cytosolic incubations, the formation of M1 was inhibited only by 2,3-dichloro- $\alpha$-methylbenzylamine (DCMB), an inhibitor of thiol S-methyltransferase (TMT), providing evidence that TMT catalyzed the formation of M1. Interestingly, the $\mathrm{N}$-methylbenzimidazole regioisomer (M14) was only observed in vitro, predominantly during incubations with human kidney cytosol and rhHNMT. The formation of M14 was inhibited by amodiaquine (an HNMT inhibitor) and DCMB, providing additional evidence that both HNMT and TMT catalyzed M14 formation. Overall, using BI 187004 as a substrate, this study demonstrates a novel TMT-mediated $\mathrm{N}$-methylation biotransformation and an HNMT-mediated regioselective $\mathrm{N}$-methylation.

\section{Introduction}

Xenobiotic methylation is a conjugation reaction catalyzed by methyltransferases located in hepatic and extrahepatic tissues. Methyltransferases catalyze the transfer of a methyl group from $S$ - $\left(5^{\prime}\right.$ adenosyl) $-L$-methionine (SAM) to substrates containing an $-O,-S$, or $-N$ heteroatom. More than 100 methyltransferase enzymes have been discovered, with only a select few exhibiting human genetic polymorphisms (Weinshilboum et al., 1999). Polymorphic methyltransferase enzymes include catechol $O$-methyltransferase (COMT), histamine $N$ methyltransferase (HNMT), thiopurine $S$-methyltransferase (TPMT), and thiol $S$-methyltransferase (TMT) (Price et al., 1989; Lachman et al., 1996; Preuss et al., 1998; Wang and Weinshilboum, 2006).

COMT catalyzes the $O$-methylation of biogenic catecholamines as well as catechol-containing drugs such as levodopa and methyldopa (Mannisto and Kaakkola, 1999). Interestingly, COMT also catalyzes the $N$-methylation of benzimidazole (Arnett et al., 1977). Polymorphisms within the COMT gene express low-activity $\operatorname{COMT}\left(C O M T^{L}\right)$ and highactivity $C O M T\left(C O M T^{H}\right)$ enzymes, with both variants expressed at approximately $25 \%$ allelic frequency in the Caucasian population,

https://doi.org/10.1124/dmd.117.079764.

S This article has supplemental material available at dmd.aspetjournals.org. whereas about $50 \%$ of the population is heterozygous with intermediate COMT activity. In the African American and Asian populations, the COMT $^{H}$ frequency is about $55 \%$ and $70 \%-80 \%$, respectively (McLeod et al., 1994; Weinshilboum et al., 1999). HNMT $N$-methylates endogenous histamine, and methylating activity can vary up to 5-fold among individuals (Weinshilboum et al., 1999). A number of thiol-containing drugs, such as 6-mercaptopurine, undergo $S$-methylation by TPMT. TPMT expression varies in Caucasians because $0.3 \%$ of the population are homozygous $\left(T P M T^{L} / T P M T^{L}\right)$ for the low-activity enzyme; $11 \%$ are heterozygous (TPMT $T^{L} / T P M T^{H}$ ), resulting in intermediate activity; and $89 \%$ are homozygous $\left(T P M T^{H} / T P M T^{H}\right)$ for the high-activity enzyme (Weinshilboum, 2001). In Asians, TPMT activity is high with a unimodal distribution due to the lack of TPMT $T^{L}$ allele (Jang et al., 1996). TMT is responsible for the $S$-methylation of captopril and ziprasidone, and, most recently, the $S$-methylation of the pharmacologically active metabolites of clopidogrel and prasugrel (Keith et al., 1984; Obach et al., 2012; Kazui et al., 2014; Liu et al., 2015). Although the gene that encodes TMT has yet to be identified, it was reported that TMT activity varies 5-fold among the Caucasian population (Keith et al., 1983b; Glauser et al., 1992).

BI 187004, (4aR,9aS)-1-(1H-benzo[d]imidazole-5-carbonyl)-2,3,4,4a,9,9ahexahydro-1H-indeno[2,1-b]pyridine-6-carbonitrile, is an 11 $\beta$-HSD1 inhibitor intended to treat type 2 diabetes mellitus (T2D). After a multiple rising-dose

ABBREVIATIONS: AUC, area under the plasma concentration-time curve; BI 187004, (4aR,9aS)-1-(1H-benzo[d]imidazole-5-carbonyl)-2,3,4,4a,9,9ahexahydro-1H-indeno[2,1-b]pyridine-6-carbonitrile; COMT, catechol O-methyltransferase; DCMB, 2,3-dichloro- $\alpha$-methylbenzylamine; DMSO, dimethylsulfoxide; ESI, electrospray ionization; FT, Fourier transform; GNMT, glycine N-methyltransferase; HKC, human kidney cytosol; HKM, human kidney microsome; HLC, human liver cytosol; HLM, human liver microsome; HNMT, histamine $N$-methyltransferase; HPLC, high-performance liquid chromatography; HSD, 11 $\beta$-hydroxysteroid dehydrogenase 1; LC, liquid chromatography; M1, $N$-methylbenzimidazole regioisomer 1; M14, $\mathrm{N}$-methylbenzimidazole regioisomer 2; $\mathrm{m} / \mathrm{z}$, charge/mass ratio; MRM, multiple reaction monitoring; MS, mass spectrometry; MS/MS, tandem mass spectrometry; NNMT, nicotinamide $N$-methyltransferase; SAM, $S$-(5'-adenosyl)- $L$-methionine; T2D, type 2 diabetes mellitus; THF, tetrahydrofuran; TMT, thiol S-methyltransferase; TPMT, thiopurine S-methyltransferase; V, formation rate. 
TABLE 1

HPLC retention time (Rt) and high-resolution MS data for BI 187004 and its metabolites identified in human plasma

\begin{tabular}{llccccc}
\hline \multicolumn{1}{c}{ Analyte } & \multicolumn{1}{c}{ Biotransformation } & Rt $(\mathrm{min})$ & Measured & Ion & Formula & Error (ppm) \\
\hline BI 187004 & \multicolumn{1}{c}{ Parent } & 18.1 & 343.1545 & {$[\mathrm{M}+\mathrm{H}]^{+}$} & $\mathrm{C}_{21} \mathrm{H}_{19} \mathrm{ON}_{4}$ & -2.6 \\
M1 & Benzimidazole $N$-methylation & 18.6 & 357.1721 & {$\left[\mathrm{M}+\mathrm{H}^{+}\right.$} & $\mathrm{C}_{22} \mathrm{H}_{21} \mathrm{ON}_{4}$ & 3.1 \\
M2 & Benzimidazole $N$-methylation + oxidation & 21.4 & 373.1654 & {$\left[\mathrm{M}+\mathrm{H}^{+}\right.$} & $\mathrm{C}_{22} \mathrm{H}_{21} \mathrm{O}_{2} \mathrm{~N}_{4}$ & -1.5 \\
M3 & Benzimidazole $N$-oxidation & 20.4 & 359.1502 & {$\left[\mathrm{M}+\mathrm{H}^{+}\right.$} & $\mathrm{C}_{21} \mathrm{H}_{19} \mathrm{O}_{2} \mathrm{~N}_{4}$ & -0.1 \\
M4 & Oxidation + desaturation & 21.5 & 357.1346 & {$\left[\mathrm{M}+\mathrm{H}^{+}\right.$} & $\mathrm{C}_{21} \mathrm{H}_{17} \mathrm{O}_{2} \mathrm{~N}_{4}$ & -0.1 \\
M5 & Oxidation & 16.6 & 359.1496 & {$\left[\mathrm{M}+\mathrm{H}^{+}\right.$} & $\mathrm{C}_{21} \mathrm{H}_{19} \mathrm{O}_{2} \mathrm{~N}_{4}$ & -1.8 \\
M6 & Benzimidazole $N$-methylation + oxidation & 16.9 & 373.1652 & {$\left[\mathrm{M}+\mathrm{H}^{+}\right.$} & $\mathrm{C}_{22} \mathrm{H}_{21} \mathrm{O}_{2} \mathrm{~N}_{4}$ & -2.0 \\
M7 & Oxidation & 16.2 & 359.1497 & {$\left[\mathrm{M}+\mathrm{H}^{+}\right.$} & $\mathrm{C}_{21} \mathrm{H}_{19} \mathrm{O}_{2} \mathrm{~N}_{4}$ & -1.7 \\
M8 & Benzimidazole $N$-methylation + oxidation & 16.5 & 373.1651 & {$\left[\mathrm{M}+\mathrm{H}^{+}\right.$} & $\mathrm{C}_{22} \mathrm{H}_{21} \mathrm{O}_{2} \mathrm{~N}_{4}$ & -2.1 \\
M9 & Benzimidazole $N$-glucuronidation & 18.2 & 519.1866 & {$[\mathrm{M}+\mathrm{H}]^{+}$} & $\mathrm{C}_{27} \mathrm{H}_{27} \mathrm{O}_{7} \mathrm{~N}_{4}$ & -1.6 \\
M10 & Oxidation + desaturation & 17.1 & 357.1341 & {$\left[\mathrm{M}+\mathrm{H}^{+}\right.$} & $\mathrm{C}_{21} \mathrm{H}_{17} \mathrm{O}_{2} \mathrm{~N}_{4}$ & -1.5 \\
M11 & Di-oxidation & 14.6 & 375.1447 & {$[\mathrm{M}+\mathrm{H}]^{+}$} & $\mathrm{C}_{21} \mathrm{H}_{19} \mathrm{O}_{3} \mathrm{~N}_{4}$ & -1.2 \\
M12 & Di-oxidation & 16.7 & 375.1442 & {$[\mathrm{M}+\mathrm{H}]^{+}$} & $\mathrm{C}_{21} \mathrm{H}_{19} \mathrm{O}_{3} \mathrm{~N}_{4}$ & -2.4 \\
M13 & Nitrile hydrolysis & 16.1 & 362.1499 & {$\left[\mathrm{M}+\mathrm{H}^{+}\right.$} & $\mathrm{C}_{21} \mathrm{H}_{20} \mathrm{O}_{3} \mathrm{~N}_{3}$ & -0.1 \\
\hline
\end{tabular}

study in Caucasian patients with T2D, during which patients were administered an 80-mg oral dose of BI 187004 once daily for 14 days, an abundant $\mathrm{N}$-methylbenzimidazole metabolite [N-methylbenzimidazole regioisomer 1 (M1)] was identified in plasma. Of eight patients treated, M1 exposure was 7-fold higher in four patients, suggesting the involvement of a polymorphic methyltransferase drug-metabolizing enzyme. The objective of this study was to identify the polymorphic methyltransferases responsible for BI 187004 benzimidazole $N$-methylation.

\section{Materials and Methods}

Chemicals and Reagents. Acetic acid, formic acid, SAM, potassium phosphate monobasic, potassium phosphate dibasic, tolcapone, amodiaquine dihydrochloride dihydrate, chloroquine diphosphate salt, sulfasalazine, histamine, 1 -methylhistamine dihydrochloride, and 1-naphthyl- $\beta$-D-glucuronide were obtained from Sigma-Aldrich (St. Louis, MO). Magnesium chloride hexahydrate and 6-methylmercaptopurine were purchased from Fisher Scientific (Pittsburgh, PA). LY78335 [2,3-dichloro- $\alpha$-methylbenzylamine (DCMB) hydrochloride] and 6-mercaptopurine were from Tocris Bioscience (Bristol, UK). 7- $\alpha$-Thiospironolactone and $7-\alpha$-thiomethyl spironolactone were obtained from Toronto Research Chemicals (Toronto, ON, Canada). 3', 4'-Dihydroxyacetophenone was from Matrix Scientific (Columbia, SC). Pooled HLM (75 males and 75 females, 18-82 years of age) were purchased from Corning Life Sciences (Woburn, MA). Pooled HLC (26 males and 24 females, 4-76 years of age), HKM (5 males and 3 females, 42-58 years of age), and HKC ( 2 males and 2 females, 45-62 years of age) were obtained from Xenotech (Lenexa, KS). Recombinant human (rh) COMT, rhHNMT, rh nicotinamide $N$-methyltransferase (NNMT), and rh glycine $N$-methyltransferase (GNMT) were from R\&D Systems (Minneapolis, MN). rhTPMT was obtained from Novus Biologicals (Littleton, CO). HPLC-grade solvents [acetonitrile, methanol, water, and dimethylsulfoxide (DMSO)] were purchased from Sigma-Aldrich. BI 187004 (Wei et al., 2016), ${ }^{13} \mathrm{C}_{6}$-BI 187004 (Latli et al., 2017), M1, and $N$-methylbenzimidazole regioisomer 2 (M14) were synthesized internally at Boehringer Ingelheim Pharmaceuticals, Inc. (Ridgefield, CT).

Chemical Synthesis of M1. (4aR,9aS)-2,3,4,4a,9,9a-hexahydro- $1 \mathrm{H}-$ indeno[2,1-b]pyridine-6-carbonitrile $(0.91 \mathrm{~g}, 4.59 \mathrm{mmol})$ and 1-methyl-1Hbenzimidazole-5-carboxylic acid (1.02 g, 95.0\%, $5.51 \mathrm{mmol}, 1.2 \mathrm{Eq})$ were added into a $100-\mathrm{ml}$ round-bottom flask. Anhydrous acetonitrile $(5 \mathrm{ml})$ was added, and stirring was started to obtain a slurry. Triethylamine $(2.56 \mathrm{ml}, 18.38 \mathrm{mmol}, 4.0$ Eq) was added at room temperature. The reaction mixture was cooled to approximately $3^{\circ} \mathrm{C}$ and propane phosphonic acid anhydride $[3.05 \mathrm{~g}, 50 \mathrm{wt} . \%$ in tetrahydrofuran (THF), $4.80 \mathrm{mmol}, 1.05 \mathrm{Eq}]$ was added dropwise, keeping the internal temperature below $11^{\circ} \mathrm{C}$. The resulting slurry was stirred at room temperature and monitored by HPLC and LC-MS for conversion. After 20 hours at room temperature, the reaction reached approximately $98 \%$ conversion. Water $(5 \mathrm{ml})$ was added dropwise, keeping the internal temperature below $35^{\circ} \mathrm{C}$. Subsequently, a 50\% sodium hydroxide aqueous solution $(1.84 \mathrm{~g}, 22.97 \mathrm{mmol}$, $5.0 \mathrm{Eq})$ was added. The resulting mixture was stirred at room temperature for 2 hours. The mixture was extracted with 2-methyl-THF $(2 \times 50 \mathrm{ml})$, and the layers were separated. The combined organic layers were dried over anhydrous magnesium sulfate $\left(\mathrm{MgSO}_{4}\right)$, filtered and concentrated to give a crude oil, which
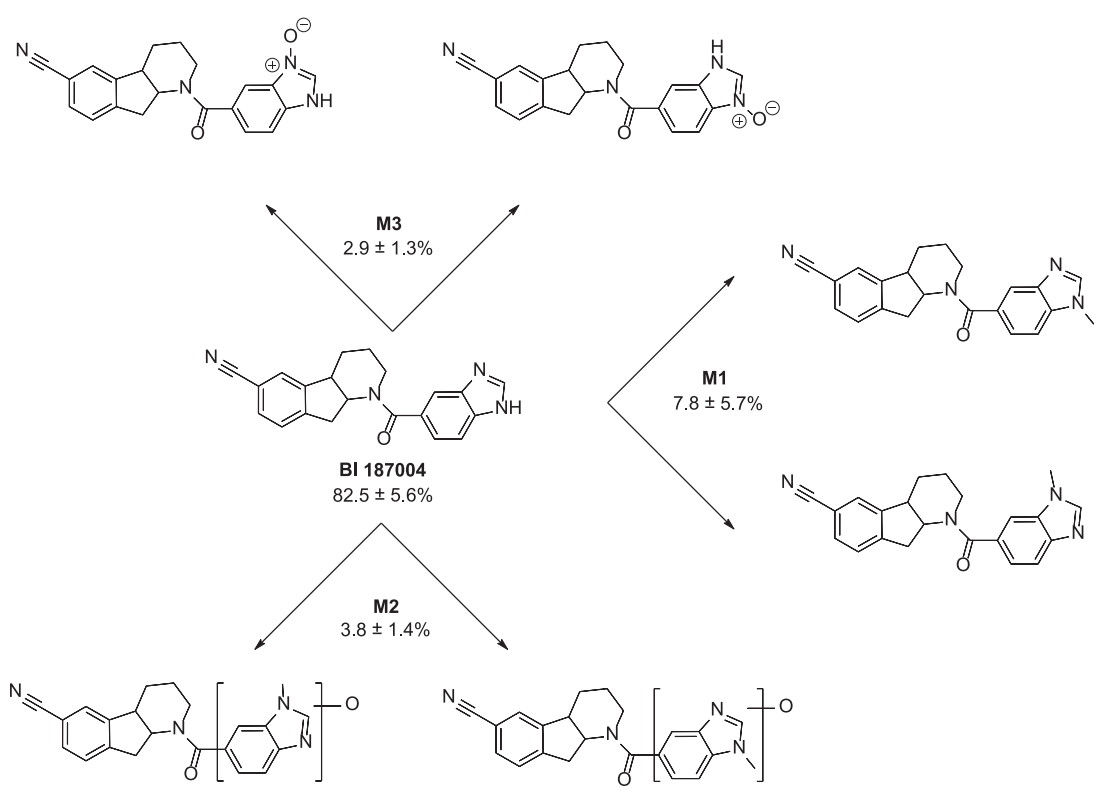

Fig. 1. Major metabolic pathways of BI 187004 and corresponding plasma AUC (mean \pm S.D.) from eight patients. 


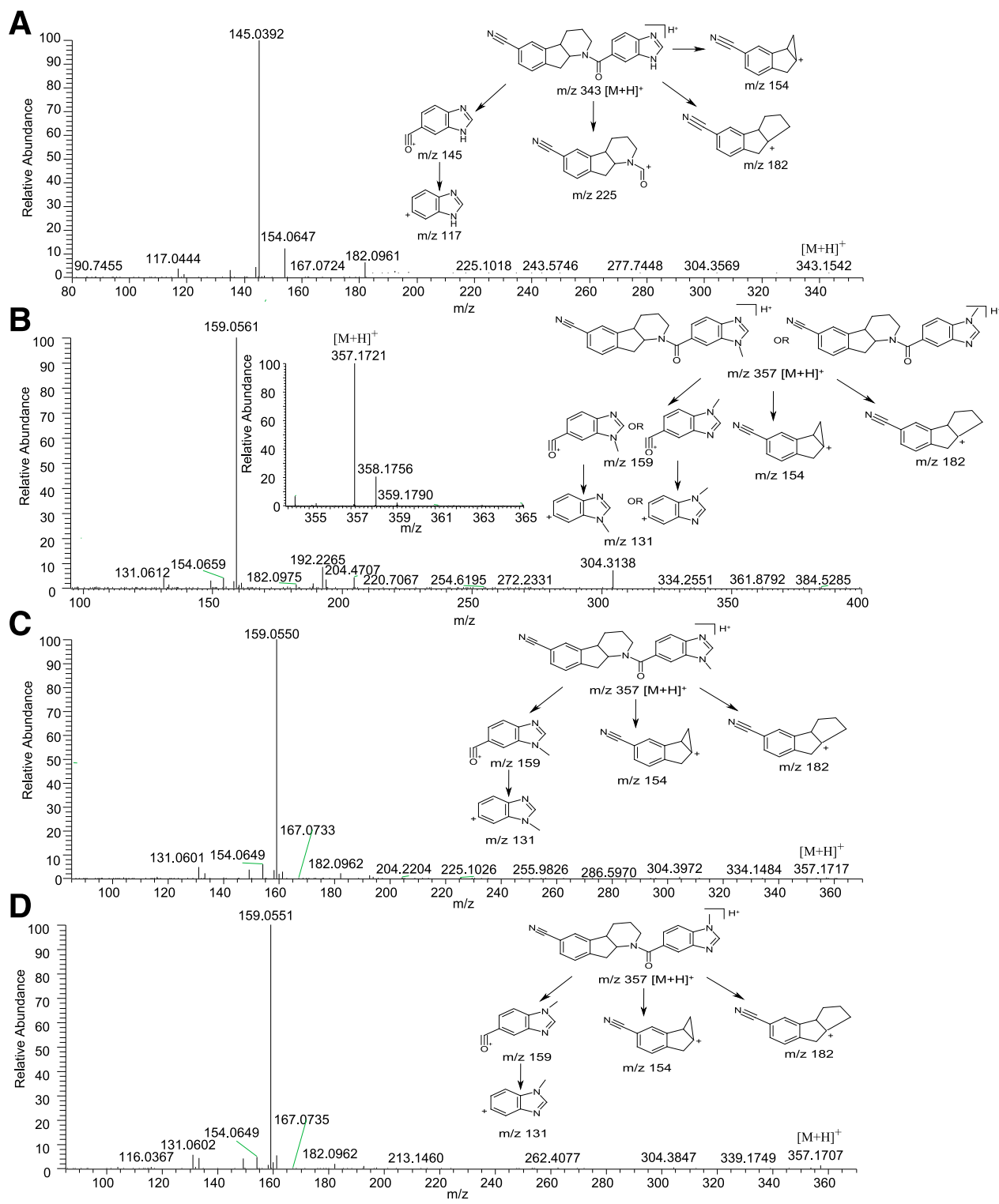

Fig. 2. Accurate mass positive product ion mass spectrum and proposed product ions of BI 187004 reference standard (A); M1 in patient plasma (B), with inset showing an m/z 353-365; M1 chemical standard (C); and M14 chemical standard (D).

was purified by flash chromatography (100 g silica gel $230-400 \mathrm{mesh}$ ) by elution with pure ethyl acetate first, and then a solution of 5\%-20\% methanol in ethyl acetate. The fractions containing the desired product were pooled together and concentrated under vacuum to give (4aR,9aS)-1-(1-methyl-1H-benzo[d]imidazole-5-carbonyl)-2,3,4,4a,9,9a-hexahydro-1H-indeno[2,1-b]pyridine6-carbonitrile ( $N$-methylbenzimidazole regioisomer 1, M1) as an off-white solid ( $1.50 \mathrm{~g}, 91.6 \%$ yield). The identity of M1 was confirmed by NMR analysis $\left({ }^{1} \mathrm{H}\right.$, ${ }^{13} \mathrm{C}$, correlation spectroscopy, rotating-frame nuclear Overhauser effect correlation spectroscopy, heteronuclear multiple quantum coherence, and heteronuclear multiple bond coherence) in DMSO- $\mathrm{d}_{6}$ at $80^{\circ} \mathrm{C}$ (Supplemental Figs. 1-6). ${ }^{1} \mathrm{H}$ NMR $\left(\mathrm{CD}_{3} \mathrm{SOCD}_{3}, 600 \mathrm{MHz}, 353 \mathrm{~K}\right) \delta 8.18(\mathrm{~s}, 1 \mathrm{H}), 7.67(\mathrm{~d}, J=1.2 \mathrm{~Hz}, 1 \mathrm{H})$, $7.63(\mathrm{~s}, 1 \mathrm{H}), 7.58(\mathrm{~d}, J=8.4 \mathrm{~Hz}, 1 \mathrm{H}), 7.55(\mathrm{dd}, J=7.8$ and $1.8 \mathrm{~Hz}, 1 \mathrm{H}), 7.41(\mathrm{~d}, J$ $=7.8 \mathrm{~Hz}, 1 \mathrm{H}), 7.32(\mathrm{dd}, J=7.8$ and $1.8 \mathrm{~Hz}, 1 \mathrm{H}), 4.80(\mathrm{br}, 1 \mathrm{H}), 4.05(\mathrm{br}, 1 \mathrm{H}), 3.84$ $(\mathrm{s}, 3 \mathrm{H}), 3.24(\mathrm{dd}, J=16.2$ and $10.8 \mathrm{~Hz}, 1 \mathrm{H}), 3.14(\mathrm{dt}, J=11.4$ and $6.6 \mathrm{~Hz}, 1 \mathrm{H})$, 2.95-3.05 (m, 2H), 1.98-2.04 (m, 1H), 1.59-1.65 (m, 1H), 1.47-1.56 (m, 1H), $1.28-1.36(\mathrm{~m}, 1 \mathrm{H}) .{ }^{13} \mathrm{C} \mathrm{NMR}\left(\mathrm{CD}_{3} \mathrm{SOCD}_{3}, 150 \mathrm{MHz}\right) \delta 170.45,147.16,145.40$, $145.29,142.53,134.81,130.34,129.72,126.61,125.67,120.63,118.50,117.31$, $109.65,109.05,54.80,41.00,39.50$ (br), 32.16, 30.20, 27.24, 22.44. LC-MS calculated for $\mathrm{C}_{22} \mathrm{H}_{20} \mathrm{~N}_{4} \mathrm{O}[\mathrm{M}+\mathrm{H}]^{+}: 357.17$, Found: 357.20 .

Chemical Synthesis of M14. (4aR,9aS)-2,3,4,4a,9,9a-hexahydro- $1 \mathrm{H}-$ indeno[2,1-b]pyridine-6-carbonitrile $(0.68 \mathrm{~g}, 3.44 \mathrm{mmol})$ and 1-methyl-1H- benzimidazole-6-carboxylic acid $(0.77 \mathrm{~g}, 95.0 \%, 4.13 \mathrm{mmol}, 1.2 \mathrm{Eq})$ were added into a $50 \mathrm{ml}$ round bottom flask. Anhydrous acetonitrile $(3.4 \mathrm{ml})$ was added and stirring was started to obtain a slurry. Triethylamine $(1.92 \mathrm{ml}, 13.76 \mathrm{mmol}, 4.0$ Eq) was added at room temperature. The reaction mixture was cooled to ca. $0^{\circ} \mathrm{C}$ and propane phosphonic acid anhydride (1.42 g, $50 \mathrm{wt}$ \% in THF, $2.23 \mathrm{mmol}$, $0.65 \mathrm{Eq}$ ) was added dropwise keeping internal temperature below $11^{\circ} \mathrm{C}$. The resulting clear solution was stirred at room temperature and monitored by HPLC and LC-MS for conversion. After 18 hours at room temperature, the reaction reached ca. $93 \%$ conversion. Water $(3.4 \mathrm{ml})$ was added dropwise keeping internal temperature below $35^{\circ} \mathrm{C}$. Subsequently, a $50 \%$ sodium hydroxide aqueous solution $(1.38 \mathrm{~g}, 17.20 \mathrm{mmol}, 5.0 \mathrm{Eq})$ was added and the resulting mixture was stirred at room temperature for 4 hours. The mixture was extracted with 2-methylTHF $(2 \times 50 \mathrm{ml})$, and the layers were separated. The combined organic layers were dried over anhydrous $\mathrm{MgSO}_{4}$, filtered, and concentrated to give a crude oil, which was purified by flash chromatography (100 g silica gel 230-400 mesh) eluted with pure ethyl acetate first, and then a solution of 5\%-30\% methanol in ethyl acetate. The fractions containing the desired product were pooled together and concentrated under vacuum to give (4aR,9aS)-1-(1-methyl-1H-benzo[d]imidazole-6-carbonyl)-2,3,4,4a,9,9a-hexahydro-1H-indeno[2,1-b]pyridine-6carbonitrile (M14) as an off-white solid $(0.91 \mathrm{~g}, 74.2 \%$ yield). The identity of M14 was confirmed by NMR analysis $\left({ }^{1} \mathrm{H},{ }^{13} \mathrm{C}\right.$, correlation spectroscopy, 


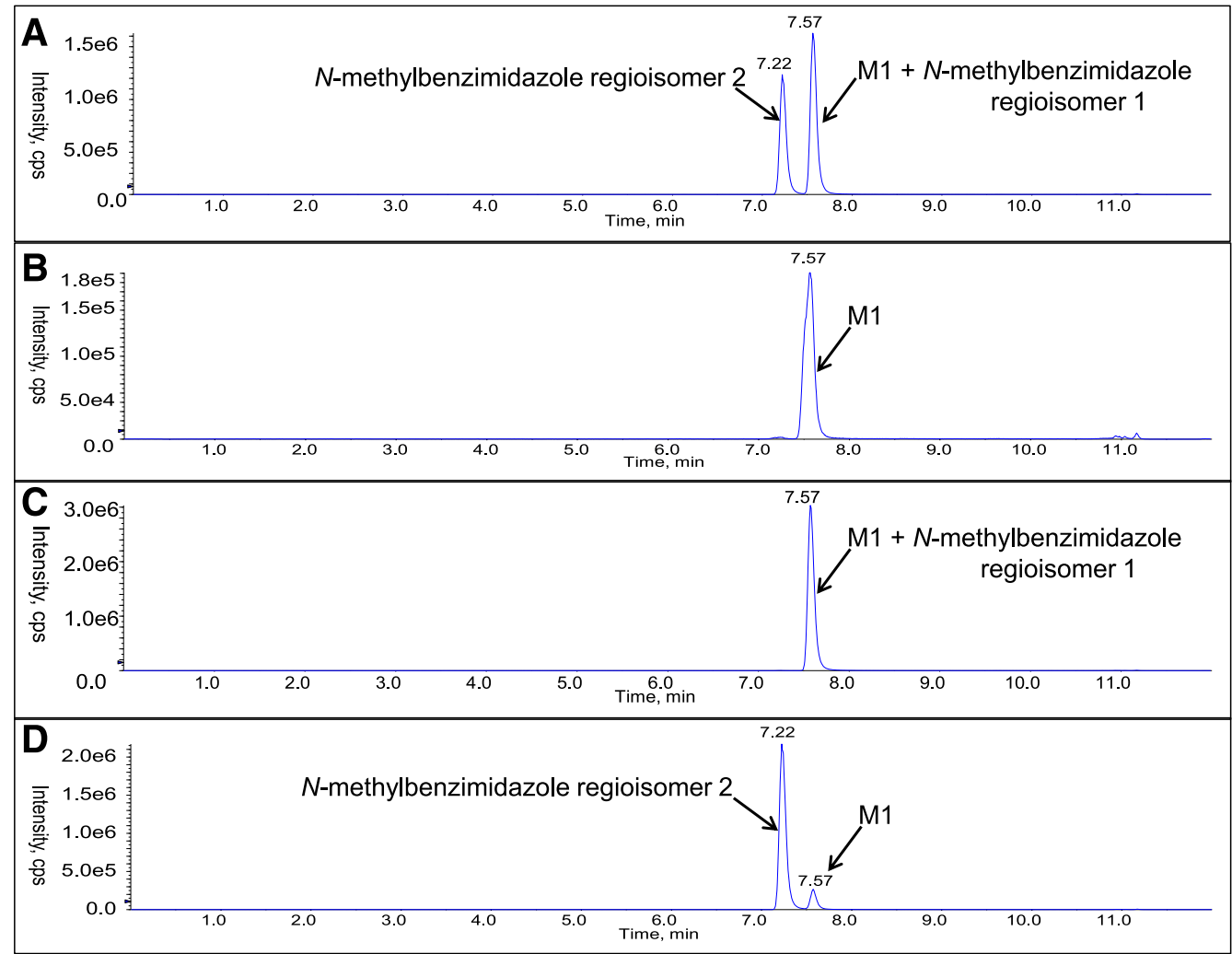

Fig. 3. Representative MRM chromatograms. (A) Patient plasma spiked with $N$-methylbenzimidazole regioisomer 1 and 2 chemical standards. (B) M1 identified in patients treated with BI 187004. (C) Patient plasma spiked with M1 chemical standard. (D) Patient plasma spiked with M14 chemical standard.

rotating-frame nuclear Overhauser effect correlation spectroscopy, heteronuclear multiple quantum coherence, and heteronuclear multiple bond coherence) in DMSO- $\mathrm{d}_{6}$ at $80^{\circ} \mathrm{C}$ (Supplemental Figs. 7-12). ${ }^{1} \mathrm{H}$ NMR $\left(\mathrm{CD}_{3} \mathrm{SOCD}_{3}, 600 \mathrm{MHz}, 353 \mathrm{~K}\right) \delta 8.18(\mathrm{~s}, 1 \mathrm{H}), 7.67(\mathrm{dd}, J=8.4$ and $0.6 \mathrm{~Hz}$, $1 \mathrm{H}), 7.63(\mathrm{~s}, 1 \mathrm{H}), 7.62(\mathrm{q}, J=0.6 \mathrm{~Hz}, 1 \mathrm{H}), 7.55(\mathrm{dd}, J=7.8$ and $1.2 \mathrm{~Hz}, 1 \mathrm{H})$, $7.42(\mathrm{~d}, J=7.8 \mathrm{~Hz}, 1 \mathrm{H}), 7.24(\mathrm{dd}, J=7.8$ and $1.2 \mathrm{~Hz}, 1 \mathrm{H}), 4.83(\mathrm{br}, 1 \mathrm{H})$, $4.05(\mathrm{br}, 1 \mathrm{H}), 3.86(\mathrm{~s}, 3 \mathrm{H}), 3.24(\mathrm{dd}, J=16.2$ and $10.2 \mathrm{~Hz}, 1 \mathrm{H}), 3.15(\mathrm{dt}, J=$ 12.0 and $6.6 \mathrm{~Hz}, 1 \mathrm{H}), 2.97-3.07(\mathrm{~m}, 2 \mathrm{H}), 1.99-2.05(\mathrm{~m}, 1 \mathrm{H}), 1.60-1.65(\mathrm{~m}$, $1 \mathrm{H}), 1.47-1.56(\mathrm{~m}, 1 \mathrm{H}), 1.29-1.37(\mathrm{~m}, 1 \mathrm{H}) .{ }^{13} \mathrm{C} \mathrm{NMR}\left(\mathrm{CD}_{3} \mathrm{SOCD}_{3}\right.$, $150 \mathrm{MHz}) \delta 170.37,147.16,145.45,145.41,143.60,133.90,130.43$, $130.35,126.63,125.68,119.59,118.70,118.50,109.05,108.49,54.72$, 41.02, 39.50 (br), 32.21, 30.23, 27.25, and 22.43. LC-MS calculated for $\mathrm{C}_{22} \mathrm{H}_{20} \mathrm{~N}_{4} \mathrm{O}\left([\mathrm{M}+\mathrm{H}]^{+}\right.$, 357.17; Found, 357.20).

Metabolite Identification. Plasma from eight patients, each of which was administered an 80-mg oral dose of BI 187004 once daily for 14 days, was collected on day 14 to identify circulating metabolites. The multiple risingdose clinical trial was carried out in compliance with the principles of the Declaration of Helsinki, in accordance with the International Conference on Harmonization-Good Clinical Practice, in accordance with applicable regulatory requirements and Boehringer Ingelheim standard operating procedures.
All subjects were informed about the trial verbally and in writing by the investigator and provided written informed consent according to good clinical practice and local legal requirements before the initiation of any trial-related procedure.

Initially, individual plasma samples were prepared according to the timeproportional sample-pooling procedure (Hop et al., 1998) to generate an AUC pool. The AUC pooled plasma was mixed with two volumes of acetonitrile containing $0.1 \%$ acetic acid, vortexed, and stored at $4^{\circ} \mathrm{C}$ for 30 minutes to improve plasma protein precipitation. Next, the samples were centrifuged at $10,000 \mathrm{~g}$ for 10 minutes at room temperature to remove precipitated proteins, and the resulting supernatant was evaporated to dryness under a stream of nitrogen. The residues were reconstituted in methanol and $0.1 \%$ formic acid in water $(1: 1, \mathrm{v} / \mathrm{v})$ and analyzed by LC-MS.

The LC-MS system consisted of an LTQ Orbitrap XL Mass Spectrometer (Thermo Fisher Scientific, Waltham, MA) and Shimadzu LC-20AD Pumps (Shimadzu Scientific Instruments, Columbia, MD). Chromatographic separation was performed at ambient temperature using an ACE 3 C18 Column $(4.6 \times 150 \mathrm{~mm}, 3 \mu \mathrm{m}$; MAC-MOD Analytical Inc., Chadds Ford, PA), starting with $100 \%$ mobile phase A $(0.1 \%$ formic acid in water) at a flow rate of $700 \mu 1 / \mathrm{min}$. The HPLC gradient was held at $0 \%$ mobile phase B

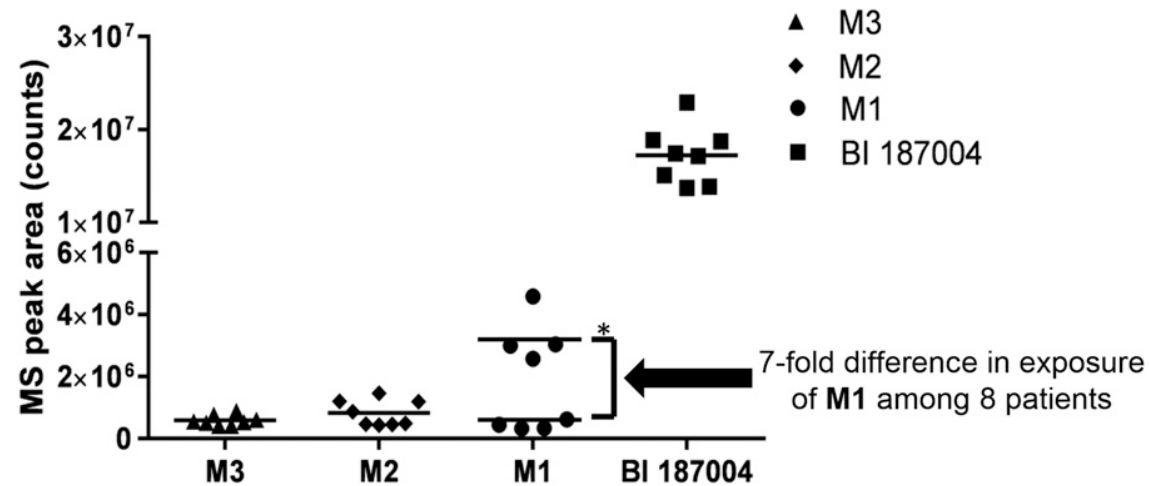

Fig. 4. Day 14 exposure of BI 187004, M1, M2, and M3 in patient plasma after an 80-mg oral dose of BI 187004 administered to eight patients for 14 days $\left({ }^{*} P<0.001\right)$. 
(acetonitrile) for 5 minutes and increased linearly to $68 \%$ B in 20 minutes, followed by an increase to $100 \%$ phase B in 5 minutes. After holding at $100 \%$ phase B for 5 minutes, the column was re-equilibrated to the initial condition for 20 minutes; the total run time was 55 minutes. The Orbitrap was equipped with an electrospray ionization (ESI) source and operated in positive ion mode. FT-MS full scans at 60,000 resolution full width at halfmaximum and subsequent data-dependent MS/MS scans were acquired. The source settings were set as follows: capillary temperature at $275^{\circ} \mathrm{C}$, sheath gas flow of 40 , auxiliary gas flow of 20 , sweep gas flow of 10 , source voltage at $4 \mathrm{kV}$, capillary voltage at $30 \mathrm{~V}$, and tube lens at $100 \mathrm{~V}$. The external calibration was performed daily using a Pierce LTQ ESI positive ion calibration mix (Thermo Fisher Scientific), and the mass accuracy was within $4 \mathrm{ppm}$. MS/MS spectra were collected after collisioninduced dissociation fragmentation acquired with an isolation width of $2 \mathrm{Da}$, normalized collision energy at $30 \mathrm{eV}$, and activation time of 30 milliseconds.

Methyltransferase Assays. BI $187004(10 \mu \mathrm{M}$, final concentration) was incubated with $3 \mathrm{mg} / \mathrm{ml} \mathrm{HLM}$, HLC, HKM, and HKC, or $1.64 \mu \mathrm{g} / \mathrm{ml}$ rhHNMT, in $50 \mathrm{mM}$ phosphate buffer $(\mathrm{pH} 7.4)$ containing $5 \mathrm{mM}$ magnesium chloride and $1 \mathrm{mM}$ SAM, in the presence and absence of isoform-selective chemical inhibitors. The final concentrations of inhibitors were $5 \mu \mathrm{M}$ tolcapone (a COMT inhibitor), $50 \mu \mathrm{M}$ amodiaquine or chloroquine (an HNMT inhibitor), $50 \mu \mathrm{M}$ sulfasalazine (a TPMT inhibitor), and $1 \mathrm{mM}$ DCMB (a TMT inhibitor). Additional incubations with BI $187004(10 \mu \mathrm{M})$ and $1.64 \mu \mathrm{g} / \mathrm{ml}$ rhCOMT, rhNNMT, rhGNMT, and rhTPMT were conducted in $50 \mathrm{mM}$ phosphate buffer (pH 7.4) containing $5 \mathrm{mM}$ magnesium chloride and $1 \mathrm{mM}$ SAM. Briefly, HLM, HLC, HKM, HKC, recombinant proteins, and BI 187004 were preincubated with or without inhibitors for 5 minutes in a water bath at $37^{\circ} \mathrm{C}$, followed by the addition of SAM to commence the reaction. The final incubation volume was $500 \mu \mathrm{l}$ and contained $\leq 1 \%$ of organic solvents. At the desired time points $(0,2,4,6$, and 24 hours $)$, the reactions were terminated by adding two volumes of an ice-cold quench solution (acetonitrile with $0.1 \%$ acetic acid containing $0.25 \mu \mathrm{M}{ }^{13} \mathrm{C}_{6}$-BI 187004). The quenched samples were centrifuged at $3500 \mathrm{rpm}$ for 30 minutes at $4^{\circ} \mathrm{C}$. Subsequently, the supernatants were analyzed by LC-MS to monitor the depletion of BI 187004 and the formation of M1 and M14.

The LC-MS system consisted of an API 4000 Triple Quadrupole Mass Spectrometer (AB Sciex, Foster City, CA) and Acquity UPLC System (Waters, Milford, MA). Chromatographic separation was performed at $50^{\circ} \mathrm{C}$ using a BEH C18 Column $(2.1 \times 50 \mathrm{~mm}, 1.7 \mu \mathrm{m}$; Waters $)$, starting with $95 \%$ mobile phase A (95\% water, $5 \%$ acetonitrile, $0.05 \%$ acetic acid) and $5 \%$ mobile phase B (95\% acetonitrile, $5 \%$ water, $0.05 \%$ acetic acid) at a flow rate of $350 \mu \mathrm{l} / \mathrm{min}$. The HPLC gradient started at $5 \% \mathrm{~B}$ and increased linearly to $30 \%$ B in 10 minutes, followed by an increase to $100 \%$ phase B in 0.5 minute. After holding at $100 \%$ B for 0.5 minute, the column was re-equilibrated to initial conditions for 0.5 minute; total run time was 11.5 minutes. Under these conditions, M1 and M14 eluted at 7.6 and 7.2 minutes, respectively, and were detected by multiple reaction monitoring $(\mathrm{MRM})$ at a charge/mass ratio $(\mathrm{m} / \mathrm{z})$ of $357.2 \rightarrow 159.2$. The internal standard, ${ }^{13} \mathrm{C}_{6}$-BI 187004 , eluted at 6.5 minutes and was detected by MRM transition at $\mathrm{m} / \mathrm{z} 349.2 \rightarrow 151.2$. The mass spectrometer was equipped with an ESI source and operated in positive ion mode at $500^{\circ} \mathrm{C}$ with ion spray voltage set at $5500 \mathrm{~V}$, an entrance potential of $10 \mathrm{~V}$, and an exit potential of $10 \mathrm{~V}$. The curtain gas was set at $30 \mathrm{psi}$, ion source gas 1 and 2 was set at $60 \mathrm{psi}$. Calibration standards were freshly prepared in inactive matrices (mixture of equal volume of HLM, HLC, HKM, HKC, or recombinant proteins). The linear calibration range was from 0.00234 to $1.20 \mu \mathrm{M}$ for M1 and M14. The calibration curves were linear with a $R^{2}$ value of $\geq 0.99$ using a $1 / \mathrm{x}^{2}$ weighting factor. Positive control incubations, with and without selective chemical inhibitors, were conducted to confirm methyltransferase activity (Supplemental Figs. 13-16).

Data Analysis. The formation rate of M1 and M14 [V (in picomoles per minute per milligram protein)] and the percentage of inhibition (\%) were calculated utilizing the following equations: A two-sample $t$ test, using SAS version 9.4 (SAS Institute Inc., Cary, NC) was applied to compare the exposure

$$
\mathrm{V}(\mathrm{pmol} / \mathrm{min} / \mathrm{mg} \text { protein })=\frac{\text { slope of metabolite formation }\left(\mu \mathrm{M} \mathrm{min}^{-1}\right) \times 1000}{\text { protein concentration }(\mathrm{mg} / \mathrm{mL})}
$$

Inhibition $(\%)=\frac{(\text { slope of metabolite formation without inhibitor }- \text { slope of metabolite formation with inhibitor }) \times 100}{\text { slope of metabolite formation without inhibitor }}$
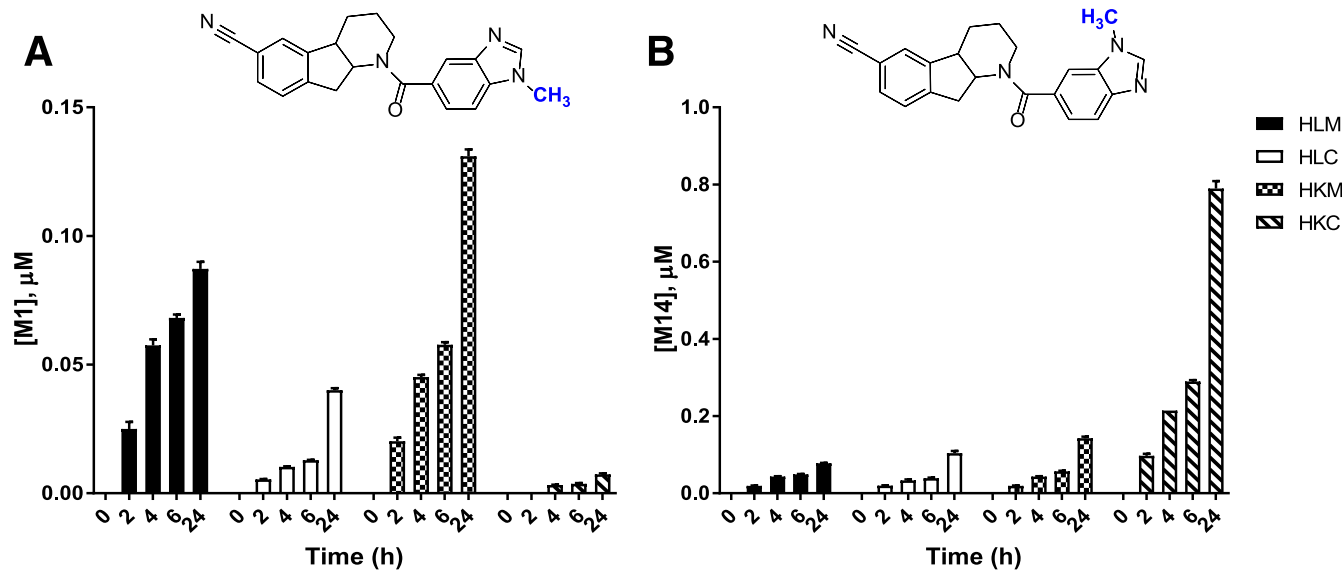

Fig. 5. BI 187004 N-methylation in HLM, HLC, HKM, and HKC. Level (micromoles) of M1 (A) and M14 (B) after incubations with BI 187004 in HLM, HLC, HKM, and $\mathrm{HKC}(3 \mathrm{mg} / \mathrm{ml})$ at $37^{\circ} \mathrm{C}$ for 24 hours in the presence of SAM. Data are reported from triplicate incubations (mean \pm S.D.). 
TABLE 2

BI $187004 N$-methylation in HLM, HLC, HKM, and HKC

Formation rates (picomoles per minute per milligram protein) of M1 and M14 after incubations with BI 187004 in HLM, HLC, HKM, and HKC $(3 \mathrm{mg} / \mathrm{ml})$ at $37^{\circ} \mathrm{C}$ for $24 \mathrm{~h}$ in the presence of SAM. Data are reported from triplicate incubations (mean \pm S.D.).

\begin{tabular}{lcc}
\hline & \multicolumn{2}{c}{$\mathrm{V}(\mathrm{pmol} / \mathrm{min} / \mathrm{mg}$ protein $)$} \\
\cline { 2 - 3 } & $\mathrm{M} 1$ & $\mathrm{M} 14$ \\
\hline HLM & $0.96 \pm 0.04$ & $0.90 \pm 0.02$ \\
HLC & $0.53 \pm 0.01$ & $1.33 \pm 0.07$ \\
HKM & $1.68 \pm 0.01$ & $1.86 \pm 0.06$ \\
HKC & $0.10 \pm 0.01$ & $10.5 \pm 0.27$ \\
\hline
\end{tabular}

differences of BI 187004 and metabolites within eight patients. A $P$ value $<0.001$ was considered to be a statistically significant difference.

\section{Results}

Metabolite Profile of BI $\mathbf{1 8 7 0 0 4}$ in Humans. Thirteen circulating metabolites were identified in seven male and one female Caucasian patients dosed with $80 \mathrm{mg}$ of BI 187004 once daily for 14 days (Table 1). The metabolic pathways of BI 187004 in human plasma were benzimidazole $N$-methylation (M1), benzimidazole $N$-methylation and oxidation (M2, M8, M6), benzimidazole $\mathrm{N}$-oxidation (M3), mono-oxidation (M7, M5), dioxidation (M11, M12), oxidation and desaturation (M4, M10), nitrile hydrolysis (M13), and benzimidazole $N$-glucuronidation (M9). BI 187004 accounted for $83 \%$ of total drug-related material, and the most abundant circulating metabolites were M1 (8\%), M2 (4\%), and M3 (3\%) in the AUC pooled plasma samples (Fig. 1). All other metabolites were minor, accounting for $<1 \%$ of the total drug-related material

M1 Structural Elucidation. The FT-MS/MS analysis of the BI 187004 showed a protonated ion at $\mathrm{m} / \mathrm{z} 343.1542$, consistent with a molecular formula of $\mathrm{C}_{21} \mathrm{H}_{19} \mathrm{ON}_{4}(-3.32 \mathrm{ppm})$. The product ion spectra of BI 187004 and the characteristic fragmentations are proposed in Fig. 2A. The major MS fragments of the molecular ion $(\mathrm{m} / \mathrm{z} \quad 343.1542)$ were $\mathrm{m} / \mathrm{z} 117.0444 \quad\left(\mathrm{C}_{7} \mathrm{H}_{5} \mathrm{~N}_{2}\right), \mathrm{m} / \mathrm{z} 145.0392$ $\left(\mathrm{C}_{8} \mathrm{H}_{5} \mathrm{ON}_{2}\right), \mathrm{m} / \mathrm{z} 154.0647\left(\mathrm{C}_{11} \mathrm{H}_{8} \mathrm{~N}\right), \mathrm{m} / \mathrm{z} 182.0961\left(\mathrm{C}_{13} \mathrm{H}_{12} \mathrm{~N}\right)$, and $\mathrm{m} / \mathrm{z} 225.1018\left(\mathrm{C}_{14} \mathrm{H}_{13} \mathrm{ON}_{2}\right)$. The FT-MS/MS of M1 in human plasma showed an accurate mass of the protonated ion at $\mathrm{m} / \mathrm{z} 357.1721$, which is consistent with a molecular formula of $\mathrm{C}_{22} \mathrm{H}_{21} \mathrm{ON}_{4}(3.11 \mathrm{ppm})$ (Fig. 2B: inset). The $[\mathrm{M}+\mathrm{H}]^{+}$of $\mathrm{M} 1$ was $14 \mathrm{Da}\left(+\mathrm{CH}_{2}\right)$ higher than that of BI 187004, which is indicative of a methylation biotransformation. The product ion spectral data of M1 and the characteristic fragmentations are proposed in Fig. 2B. The major MS fragments of the molecular ion $(\mathrm{m} / \mathrm{z} 357.1721)$ were $\mathrm{m} / \mathrm{z} 131.0612\left(\mathrm{C}_{8} \mathrm{H}_{7} \mathrm{~N}_{2}\right), \mathrm{m} / \mathrm{z}$ $154.0659\left(\mathrm{C}_{11} \mathrm{H}_{8} \mathrm{~N}\right), \mathrm{m} / \mathrm{z} 159.0561\left(\mathrm{C}_{9} \mathrm{H}_{7} \mathrm{ON}_{2}\right)$, and $\mathrm{m} / \mathrm{z} 182.0975$
$\left(\mathrm{C}_{13} \mathrm{H}_{12} \mathrm{~N}\right)$. The fragment ions at $\mathrm{m} / \mathrm{z} 159$ and $\mathrm{m} / \mathrm{z} 131$ were $14 \mathrm{Da}$ higher than the m/z 145 and m/z 117 fragments of BI 187004, suggesting that methylation occurred on one of the benzimidazole nitrogens. All other fragment ions of M1 were also consistent with the characteristic fragments of BI 187004. The FT-MS/MS of the BI $187004 \mathrm{~N}$-methylbenzimidazole regioisomer chemical standards showed an accurate mass of the protonated ion at both $\mathrm{m} / \mathrm{z}$ 357.1717 (regioisomer 1) and m/z 357.1707 (regioisomer 2), which is consistent with a molecular formula of $\mathrm{C}_{22} \mathrm{H}_{21} \mathrm{ON}_{4}( \pm 2 \mathrm{ppm})$. The product ion spectral data and characteristic fragmentations of each $\mathrm{N}$ methylbenzimidazole regioisomer chemical standard are proposed in Fig. 2, C and D, and match the MS/MS fragmentation of M1 identified in human plasma.

To determine the $\mathrm{N}$-methyl regiochemistry of M1, the BI $187004 \mathrm{~N}$ methylbenzimidazole regioisomer chemical standards were baseline separated (resolution $=1.8$ ) with retention times of 7.6 and 7.2 minutes, respectively (Fig. 3A). The retention time of M1 in patient plasma (Fig. $3 \mathrm{~B})$ matched the retention time of $N$-methylbenzimidazole regioisomer 1 , but not with $N$-methylbenzimidazole regioisomer 2 . Additionally, a mixture of the $N$-methylbenzimidazole regioisomer 1 standard spiked into patient plasma produced only one peak (Fig. 3C), whereas a mixture of $\mathrm{N}$-methylbenzimidazole regioisomer 2 and patient plasma showed two peaks (Fig. 3D), further confirming M1 as $N$-methylbenzimidazole regioisomer 1 .

M1 Human Exposure. Among eight patients treated with BI 187004, M1 exposure was 7-fold higher in four patients, indicating a substantial degree of metabolic variation $(P<0.001$ by a two-sample $t$ test) (Fig. 4). The mean age was 58 years (age range, 43-68 years); four subjects were ex-smokers, three subjects never smoked, and one subject smoked during the study. Although there were only eight patients in this study, there was no apparent trend among M1 exposure, smoking, and the age of patients within the study. Additionally, there was no intersubject variation $(P>0.001)$ regarding the plasma exposure of M2 and M3, which accounted for $4 \%$ and 3\% of total drug-related material, respectively.

In Vitro Methylation of BI 187004. Methyltransferase reaction phenotyping experiments were conducted with HLM, HLC, HKM, HKC, and recombinant enzyme preparations to determine the enzyme(s) responsible for BI $187004 N$-methylation. Initially, $1 \mu \mathrm{M} \mathrm{BI}$ 187004 was incubated for 1 hour with HLM, HLC, HKM, and HKC $(1 \mathrm{mg} / \mathrm{ml})$ in the presence of SAM. Due to low metabolic turnover, the incubations were conducted up to 24 hours with $3 \mathrm{mg} / \mathrm{ml}$ microsomal or cytosolic protein and $10 \mu \mathrm{M}$ BI 187004 (Fig. 5). In addition to M1 formation (Fig. 5A), M14, which was not circulating in patient plasma, was also observed in each of the in vitro incubations (Fig. 5B). In this
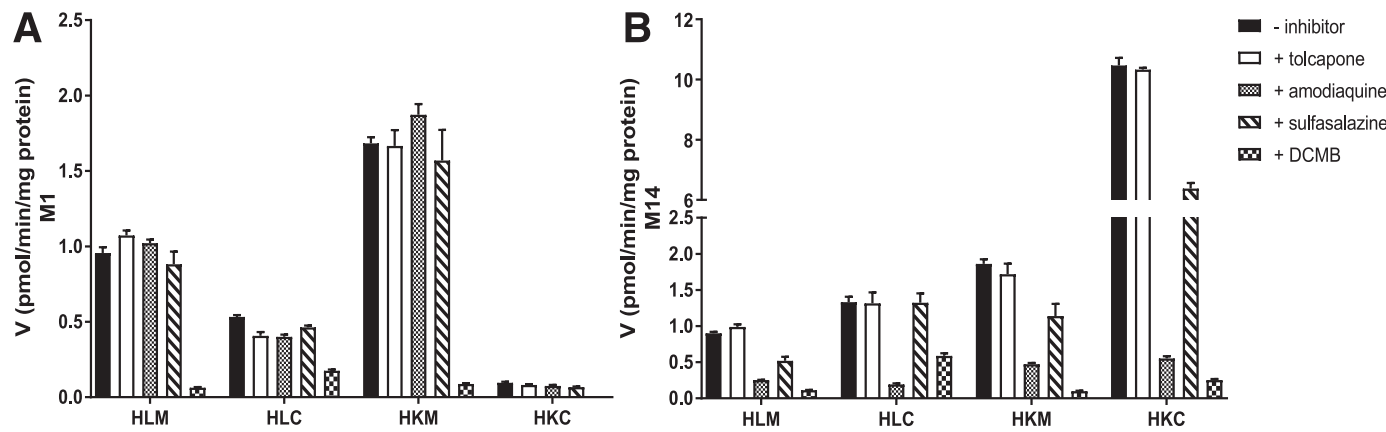

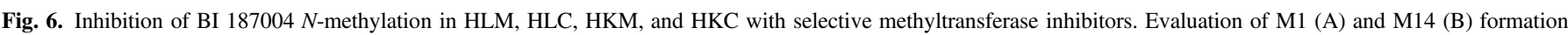

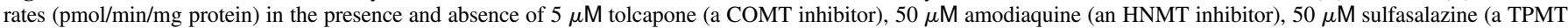
inhibitor), and $1 \mathrm{mM}$ DCMB (a TMT inhibitor). Data are reported from triplicate incubations (mean \pm S.D.). 
TABLE 3

Inhibition of the formation of M1 and M14 by selective methyltransferase chemical inhibitors in HLM, HLC, HKM, and HKC

Values are given as percentage.

\begin{tabular}{lcccc}
\hline & \multicolumn{4}{c}{ Inhibition (\%) } \\
\cline { 2 - 5 } & M1 & \multicolumn{3}{c}{ M14 } \\
\cline { 3 - 5 } & DCMB & Amodiaquine & Sulfasalazine & DCMB \\
\hline HLM & 93.3 & 71.7 & 42.2 & 87.4 \\
HLC & 67.2 & 85.5 & No inhibition & 55.8 \\
HKM & 94.7 & 74.5 & 38.7 & 94.7 \\
HKC & 100 & 94.7 & 39.1 & 97.6 \\
\hline
\end{tabular}

experiment, a maximum $2 \%$ and $8 \%$ of BI 187004 was metabolized to M1 and M14, respectively, and there was time-dependent formation of M1 and M14 in all in vitro systems tested. Only 2\% of M1 was converted back to BI 187004 when $10 \mu \mathrm{M}$ M1 was incubated with human hepatocytes (data not shown).

The formation rates of M1 and M14 in HLM, HLC, HKM, and HLC incubations are described in Table 2. M1 was principally formed in both HLM (0.96 pmol/min/mg protein) and HKM ( $1.68 \mathrm{pmol} / \mathrm{min} / \mathrm{mg}$ protein) incubations. In HLC, the M1 formation rate was $0.53 \mathrm{pmol} / \mathrm{min} / \mathrm{mg}$ protein), and in $\mathrm{HKC}$ the $\mathrm{M} 1$ production was the lowest $(0.10 \mathrm{pmol} / \mathrm{min} / \mathrm{mg}$ protein $)$ among all of the in vitro systems tested. However, M14 formation was the highest in HKC incubations (10.5 pmol/min/mg protein). In HLC, the M14 formation rate was $1.33 \mathrm{pmol} / \mathrm{min} / \mathrm{mg}$ protein and was 7.9 -fold lower than that in HKC. The M14 formation rates in liver and kidney microsomal incubations were 0.90 and $1.86 \mathrm{pmol} / \mathrm{min} / \mathrm{mg}$ protein, respectively.

Methyltransferase isoform-selective chemical inhibitors were added to the HLM, HLC, HKM, and HKC incubations to determine the specific methyltransferase responsible for BI 187004 methylation (Fig. 6). Tolcapone (a COMT inhibitor), amodiaquine (an HNMT inhibitor), and sulfasalazine (a TPMT inhibitor) did not prevent M1 formation. Interestingly, however, DCMB (an inhibitor of TMT) reduced M1 production by $67 \%$ in HLC, by $93 \%$ in HLM, by $95 \%$ in HKM, and by $100 \%$ in HKC (Table 3). The M14 regioisomer was not inhibited by tolcapone in any of the in vitro systems tested. Additionally, sulfasalazine did not inhibit M14 formation in HLC, but partially inhibited M14 formation by $39 \%$ in HKM and HKC, and by $42 \%$ in HLM. Amodiaquine and DCMB inhibited M14 production by $72 \%-95 \%$ and $56 \% \%-98 \%$, respectively (Table 3 ).

Subsequently, BI 187004 was incubated with commercially available human recombinant proteins (rhCOMT, rhHNMT, rhNNMT, rhGNMT, and rhTPMT) to substantiate the chemical inhibition results. In all the human recombinant protein incubations, there was no M1 formation (Fig. 7A). However, SAM-dependent formation of M14 was observed only in incubations with rhHNMT, and minimally with rhNNMT (Fig. 7B). The M14 formation during incubations of BI 187004 with rhHNMT was inhibited by chloroquine (an HNMT inhibitor) (Fig. 7C).

\section{Discussion}

BI 187004, an HSD inhibitor, was administered once daily for 14 days to eight patients with T2D. M1 was identified as the most abundant metabolite, and its exposure was 7-fold higher in four patients treated with BI 187004, indicating a substantial degree of metabolic variation. Although M1 exposure was $>10 \%$ of total drug-related material in four
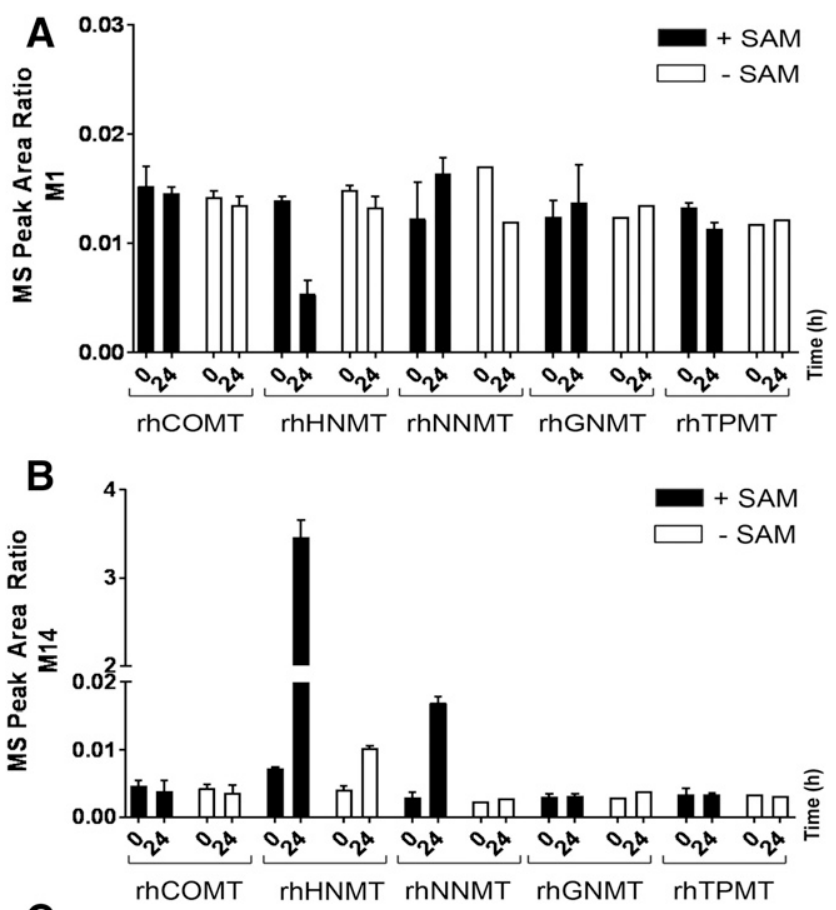

C

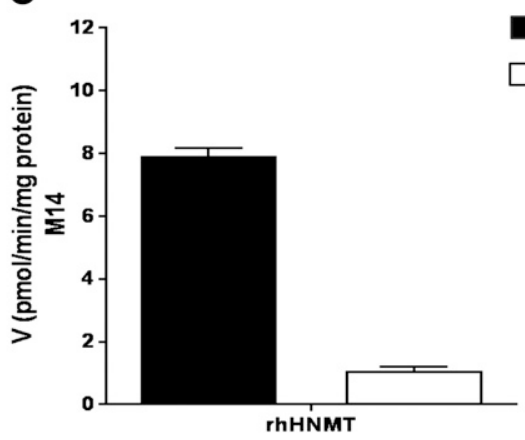

Fig. 7. BI $187004 N$-methylation with human recombinant methyltransferase enzymes and M14 inhibition by chloroquine. Level of M1 (A) and M14 (B) after incubations of $10 \mu \mathrm{M}$ BI 187004 with rhCOMT, rhHNMT, rhNNMT, rhGNMT, and rhTPMT $(1.64 \mu \mathrm{g} / \mathrm{ml})$ in the presence or absence (open bars) of SAM at $37^{\circ} \mathrm{C}$ for 24 hours. Data are reported from triplicate determinations (mean \pm S.D.) except for $n=1$ for rhNNMT, rhGNMT, and rhTPMT in the absence of SAM. MS peak area ratio (PAR) is defined as the ratio between the analyte and the internal standard. The concentrations of M1 and M14 were below the limit of quantitation, and, consequently, MS PAR was plotted on the $y$-axis in (A) and (B). (C) Evaluation of M14 formation rates (in picomoles per minute per milligram protein) after incubations with $10 \mu \mathrm{M}$ BI 187004 in $\operatorname{rhHNMT}(1.64 \mu \mathrm{g} / \mathrm{ml})$ at $37^{\circ} \mathrm{C}$ for 22 hours in the presence or absence (closed bars) of $50 \mu \mathrm{M}$ chloroquine. Data are reported from triplicate determinations (mean \pm S.D.).

of eight patients treated in the study, M1 is a conjugated metabolite and poses no human safety concern according to the International Conference on Harmonization guidance M3 (R2) and the US Food and Drug Administration Metabolites in Safety Testing guidance (European Medicines Agency, 2009; U.S. Food and Drug Administration, 2016). Additionally, drug-drug interaction investigations were unnecessary because M1 was less polar than BI 187004 and its exposure was less than $25 \%$ of the parent AUC exposurs (European Medicines Agency, 2012; U.S. Food and Drug Administration, 2017). However, the observed variability noted in the exposure of M1 may be explained by a human polymorphic methyltransferase, which could ultimately impact future dose selections and warrant patient genotyping in subsequent clinical studies. Therefore, methyltransferase 
reaction phenotyping experiments were conducted to determine which enzyme(s) catalyze BI $187004 \mathrm{~N}$-methylation.

Interestingly, the formation of M1 and M14 was linear during the extended incubation time course, demonstrating that methyltransferase enzymes and SAM were thermally stable at $37^{\circ} \mathrm{C}$ up to 24 hours. Historically, incubation times for investigating methyltransferase activity in vitro range from 10 minutes to 2 hours (Van Loon et al., 1985; Kazui et al., 2014; Liu et al., 2015). From our work, it is noteworthy that, unlike cytochrome $\mathrm{P} 450$ enzymes, methyltransferase enzymes in microsomal or cytosolic preparations can be incubated at $37^{\circ} \mathrm{C}$ for 24 hours without the loss of enzyme activity.

In both human microsomal and cytosolic incubations, M1 was observed, albeit with different formation rates. M1 was principally formed in both HLM and HKM incubations, with a 1.8-fold higher formation rate in kidney microsomes. This result indicates that M1 was primarily formed via a methyltransferase specifically located in microsomes. DCMB inhibited M1 production in HLM and HKM by $93 \%$ and $95 \%$, respectively, providing evidence that $\mathrm{M} 1$ is catalyzed by TMT. Additionally, there was no observed M1 formation utilizing any commercially available recombinant methyltransferase enzymes (COMT, HNMT, NNMT, GNMT, or TPMT). In HLC, the M1 formation rate was 1.8-fold lower than in HLM, suggesting that a liver cytosolic methyltransferase may also contribute to BI 187004 methylation. Although TMT is notably a microsomal enzyme, TMT activity in HLC has been previously reported, but only for $S$-methylation reactions (Glauser et al., 1992; Liu et al., 2015).

In kidney preparations, M14 formation was dramatically higher in the cytosolic incubations compared with all of other in vitro systems, providing evidence that M14 is formed mainly via a soluble methyltransferase. Additionally, amodiaquine and DCMB inhibited M14 production, providing evidence that both HNMT and TMT catalyze M14 formation. In this case, however, it is possible that DCMB, previously identified as a phenylethanolamine $N$-methyltransferase inhibitor (Fuller et al., 1973; Glauser et al., 1993), also inhibited HNMT in the cytosolic incubations. Although there was no M14 formation in rhTPMT incubations, the observed partial inhibition of M14 by sulfasalazine may also be attributed to HNMT inhibition by sulfasalazine. M14 was formed in rhHNMT incubations, and its formation was inhibited by chloroquine (an HNMT inhibitor), thus corroborating that M14 is formed by HNMT and TMT.

Interestingly, only M1 was identified in patient plasma. Since the M14 formation rate was 6.3-fold higher in kidney preparations compared with M1, it is plausible that M14 is clinically formed in the kidney where HNMT is highly expressed (Preuss et al., 1998), and then is rapidly excreted into the urine. Although no human samples were available at the time of our analysis to confirm this hypothesis, future in vitro experiments will include an investigation of renal transporters involved in the efflux of M1 and M14.

From a chemical perspective, BI 187004 will likely exist in aqueous solution as two tautomers. In one tautomer, the benzimidazole $\mathrm{NH}$ electron lone pair can be delocalized all the way through the carbonyl, whereas the benzimidazole NH electron lone pair of the corresponding tautomer is only delocalized within the benzimidazole ring. Theoretically, the $\mathrm{NH}$ of the tautomer with the longer electron delocalization would be more acidic, and thus more reactive, leading to the preferential formation of M1. However, in HLM and HKM where TMT is expressed, M1 and M14 are formed at nearly the same rate. We suspect that M1 is not preferentially formed by TMT, but rather that M14 is regioselectively cleared from the plasma.

In conclusion, TMT solely catalyzed M1 formation in human liver and kidney microsomal and cytosol preparations based on the observed $67 \%-100 \%$ inhibition of methylating activity by DCMB. This novel finding confirmed our initial hypothesis that a polymorphic methyltransferase may explain clinical data regarding a 7-fold difference in M1 exposure. Additionally, M14 formation was catalyzed by HNMT and TMT in vitro, demonstrating regioselective $N$-methylation by HNMT. Overall, this study provides evidence that TMT has a broad substrate specificity that is limited not only to $S$ - and $O$-methylation (Keith et al., 1983a,b; Weinshilboum, 2006), but also to $N$-methylation.

\section{Acknowledgments}

We thank Dr. Naitee Ting for help with statistical input.

\section{Authorship Contributions}

Participated in research design: Maw, Taub, and Teitelbaum.

Conducted experiments: Maw, Zeng, and Campbell.

Performed data analysis: Maw.

Wrote or contributed to the writing of the manuscript: Maw, Zeng, Campbell, Taub, and Teitelbaum.

\section{References}

Arnett CD, Callery PS, and Zenker N (1977) N-Methylation of benzimidazole by catechol-Omethyltransferase. Biochem Pharmacol 26:377-380.

European Medicines Agency (2009) ICH Topic M3 (R2) Non-Clinical Safety Studies for the Conduct of Human Clinical Trials and Marketing Authorization for Pharmaceuticals, European Medicines Agency, London, UK.

European Medicines Agency (2012) Guideline on the Investigation of Drug Interactions, European Medicines Agency, London, UK.

Fuller RW, Roush BW, Snoddy HD, and Molloy BB (1973) Inhibition of phenylethanolamine $\mathrm{N}$-methyltransferase by benzylamines. 2 . In vitro and in vivo studies with 2,3-dichloro-methylbenzylamine. J Med Chem 16:106-109.

Glauser TA, Kerremans AL, and Weinshilboum RM (1992) Human hepatic microsomal thiol methyltransferase. Assay conditions, biochemical properties, and correlation studies. Drug Metab Dispos 20:247-255.

Glauser TA, Saks E, Vasova VM, and Weinshilboum RM (1993) Human liver microsomal thiol methyltransferase: inhibition by arylalkylamines. Xenobiotica 23:657-669.

Hop CE, Wang Z, Chen Q, and Kwei G (1998) Plasma-pooling methods to increase throughput for in vivo pharmacokinetic screening. J Pharm Sci 87:901-903.

Jang IJ, Shin SG, Lee KH, Yim DS, Lee MS, Koo HH, Kim HK, and Sohn DR (1996) Erythrocyte thiopurine methyltransferase activity in a Korean population. Br J Clin Pharmacol 42:638-641.

Kazui M, Hagihara K, Izumi T, Ikeda T, and Kurihara A (2014) Hepatic microsomal thiol methyltransferase is involved in stereoselective methylation of pharmacologically active metabolite of prasugrel. Drug Metab Dispos 42:1138-1145.

Keith RA, Abraham RT, Pazmiño P, and Weinshilboum RM (1983a) Correlation of low and high affinity thiol methyltransferase and phenol methyltransferase activities in human erythrocyte membranes. Clin Chim Acta 131:257-272.

Keith RA, Jardine I, Kerremans A, and Weinshilboum RM (1984) Human erythrocyte membrane thiol methyltransferase. S-methylation of captopril, N-acetylcysteine, and 7 alpha-thio-spirolactone. Drug Metab Dispos 12:717-724.

Keith RA, Van Loon J, Wussow LF, and Weinshilboum RM (1983b) Thiol methylation pharmacogenetics: heritability of human erythrocyte thiol methyltransferase activity. Clin Pharmacol Ther 34:521-528.

Lachman HM, Papolos DF, Saito T, Yu YM, Szumlanski CL, and Weinshilboum RM (1996) Human catechol-O-methyltransferase pharmacogenetics: description of a functional polymorphism and its potential application to neuropsychiatric disorders. Pharmacogenetics 6: 243-250.

Latli B, Hrapchak M, Savoie J, Zhan Y, Busacca CA, and Senanayake CH (2017) Potent and selective inhibitors of $11 \beta$-hydroxysteroid dehydrogenase type 1 labeled with carbon-13 and carbon-14. J Labelled Comp Radiopharm 60:420-430.

Liu C, Chen Z, Zhong K, Li L, Zhu W, Chen X, and Zhong D (2015) Human liver cytochrome $\mathrm{P} 450$ enzymes and microsomal thiol methyltransferase are involved in the stereoselective formation and methylation of the pharmacologically active metabolite of clopidogrel. Drug Metab Dispos 43:1632-1641.

Männistö PT and Kaakkola S (1999) Catechol-O-methyltransferase (COMT): biochemistry, molecular biology, pharmacology, and clinical efficacy of the new selective COMT inhibitors. Pharmacol Rev 51:593-628.

McLeod HL, Fang L, Luo X, Scott EP, and Evans WE (1994) Ethnic differences in erythrocyte catechol-O-methyltransferase activity in black and white Americans. J Pharmacol Exp Ther 270: 26-29.

Obach RS, Prakash C, and Kamel AM (2012) Reduction and methylation of ziprasidone by glutathione, aldehyde oxidase, and thiol S-methyltransferase in humans: an in vitro study. Xenobiotica 42:1049-1057.

Preuss CV, Wood TC, Szumlanski CL, Raftogianis RB, Otterness DM, Girard B, Scott MC, and Weinshilboum RM (1998) Human histamine N-methyltransferase pharmacogenetics: common genetic polymorphisms that alter activity. Mol Pharmacol 53:708-717.

Price RA, Keith RA, Spielman RS, and Weinshilboum RM (1989) Major gene polymorphism for human erythrocyte (RBC) thiol methyltransferase (TMT). Genet Epidemiol 6:651-662.

U.S. Food and Drug Administration (2016) Safety Testing of Drug Metabolites: Guidance for Industry, Center for Drug Evaluation and Research, US Food and Drug Administration, US Department of Health and Human Services, Rockville, MD.

U.S. Food and Drug Administration (2017) In Vitro Metabolism- and Transporter-Mediated DrugDrug Interaction Studies Gudance for Industry, Center for Drug Evaluation and Research, US Food and Drug Administration, US Department of Health and Human Services, Rockville, MD. 
Van Loon JA, Pazmiño PA, and Weinshilboum RM (1985) Human erythrocyte histamine $\mathrm{N}$-methyltransferase: radiochemical microassay and biochemical properties. Clin Chim Acta 149 $237-251$.

Wang L and Weinshilboum R (2006) Thiopurine S-methyltransferase pharmacogenetics: insights, challenges and future directions. Oncogene 25:1629-1638.

Wei X, Qu B, Zeng X, Savoie J, Fandrick KR, Desrosiers JN, Tcyrulnikov S, Marsini MA, Buono FG, Li Z, et al. (2016) Sequential C-H arylation and enantioselective hydrogenation enables ideal asymmetric entry to the indenopiperidine core of an $11 \beta$-HSD-1 inhibitor. J Am Chem Soc 138 15473-15481.

Weinshilboum R (2001) Thiopurine pharmacogenetics: clinical and molecular studies of thiopurine methyltransferase. Drug Metab Dispos 29:601-605.
Weinshilboum RM (2006) Pharmacogenomics: catechol O-methyltransferase to thiopurine S-methyltransferase. Cell Mol Neurobiol 26:539-561.

Weinshilboum RM, Otterness DM, and Szumlanski CL (1999) Methylation pharmacogenetics: catechol O-methyltransferase, thiopurine methyltransferase, and histamine N-methyltransferase. Annu Rev Pharmacol Toxicol 39:19-52.

Address correspondence to: Hlaing $\mathrm{H}$. Maw, Drug Metabolism and Pharmacokinetics Department, Boehringer Ingelheim Pharmaceuticals, Inc., 900 Ridgebury Road, Ridgefield, CT 06877-0368. E-mail: hlaing.maw@boehringer-ingelheim.com 